\title{
Cyclic Deformation Behavior and Fatigue Crack Propagation of Low Carbon Steel Prestrained in Tension
}

\author{
J. G. Wang, ${ }^{1}$ W. P. Jia, ${ }^{2}$ and D. Y. Ju ${ }^{1}$ \\ ${ }^{1}$ Department of Material Science and Engineering, Saitama Institute of Technology, Fusaiji 1690, Fukaya, Saitama 369-0293, Japan \\ ${ }^{2}$ Department of Material Science and Engineering, University of Science and Technology Liaoning, Anshan, Liaoning 114051, China
}

Correspondence should be addressed to D. Y. Ju, dyju@sit.ac.jp

Received 30 March 2009; Accepted 20 May 2009

Recommended by Daolun Chen

The tests were performed on low carbon steel plate. In the tension fatigue tests, two angle values $\left(\phi=0^{\circ}\right.$ and $\left.\phi=45^{\circ}\right)$ have been chosen, which were the angles between the loading and the rolling direction. The influence of strain path change on the subsequent initial work softening rate and the saturation stress has been investigated. Dislocation microstructure was observed by transmission electron microscopy. It was found that the strain amount of preloading in tension has obviously affected the cyclic softening phenomenon and the initial cyclic softening rate. It was observed that the reloading axial stress for $\phi=45^{\circ}$ case increased more than that of $\phi=0^{\circ}$ case, due to the anisotropism of Q235. In the fatigue crack propagation tests, the experimental results show that with increasing the pretension deformation degree, the fatigue crack growth rate increases, especially at the near threshold section.

Copyright (C) 2009 J. G. Wang et al. This is an open access article distributed under the Creative Commons Attribution License, which permits unrestricted use, distribution, and reproduction in any medium, provided the original work is properly cited.

\section{Introduction}

Fatigue as mainly damage form in the process of using is firstly studied [1-3]. In fact, nearly $90 \%$ of total fatigue of most materials is at the stage of cyclic deformation and crack initiation, so trying to clarify cyclic deformation behavior of materials is of much importance not only in theory research, but also in engineering application. Up to date, most research works in literature about this are on the cyclic deformation behavior of annealed materials [4-6]. Recently, the cyclic deformation behavior of materials with prestrained history has also been studied because of its industrial application background [7-9]. However, some aspects about it are not very clear yet, especially polycrystallinity material; further system study is necessary. The present work is mainly about the cyclic deformation behavior and fatigue crack propagation of low carbon steel prestrained.

\section{Experimental Procedure}

Hot-rolled steel (Q235) plate was chosen for the research material, in which the chemical compositions were $0.140 \%$
C, $0.170 \% \mathrm{Si}, 0.400 \% \mathrm{Mn}, 0.012 \% \mathrm{P}$, and $0.006 \% \mathrm{~S}$ by weight, respectively. The typical microstructures of Q235 are ferrite which is an equiaxed grain structure with mean grain size of $20 \mu \mathrm{m}$, and pearlite is a lamellar grain structure.

Tension-fatigue tests: two angle values $\left(\phi=0^{\circ}\right.$ and $\phi=45^{\circ}, \phi$ is the angle between the loading and the rolling direction) have been chosen, which were the angles between the loading and the rolling direction. The strain rate for the pretension $(2 \%, 5 \%, 10 \%)$ tests is $5 \times 10^{-3} \mathrm{~s}^{-1}$. Cyclic pull-push fatigue tests were conducted under constant plastic strain amplitude controlled $\left(0.6 \times 10^{-3}, 1.5 \times 10^{-3}, 2.5 \times 10^{-3}\right)$ by Instron servohydraulic fatigue testing machine at room temperature. The triangular waveform signal was used with a frequency of $0.5 \mathrm{~Hz}$. All the fatigue tests were conducted until the specimens were saturated.

Fatigue crack testing: the pretension $(5 \%, 10 \%)$ and original specimens were tested in completely tension-tension mode at the room temperature until fracture. Load control $\left(R=\sigma_{\min } / \sigma_{\max }=0.1, f=10 \mathrm{~Hz}\right)$ is conducted for the fatigue crack testing. The fracture surfaces were observed by JSM-5410LV.

Transmission electron microscopy (TEM) was used to characterize the dislocation substructures during the second 


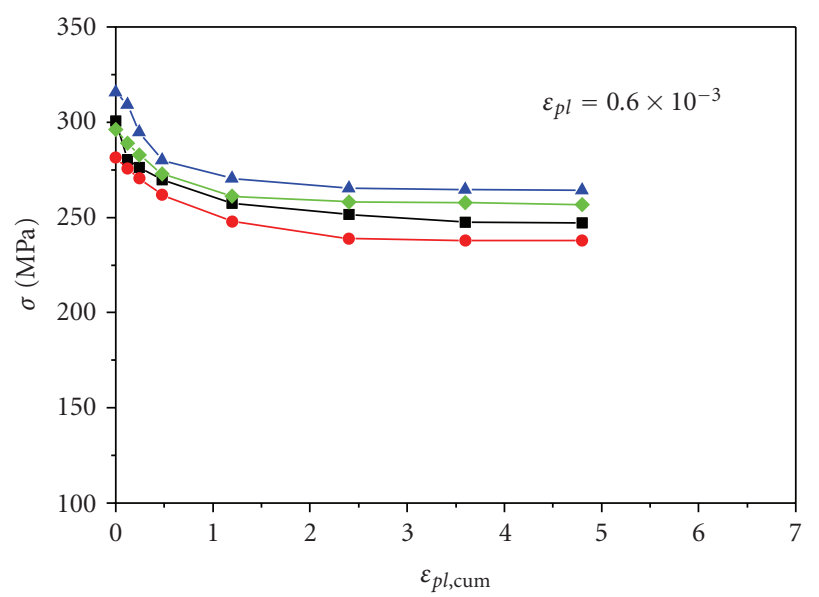

(a)

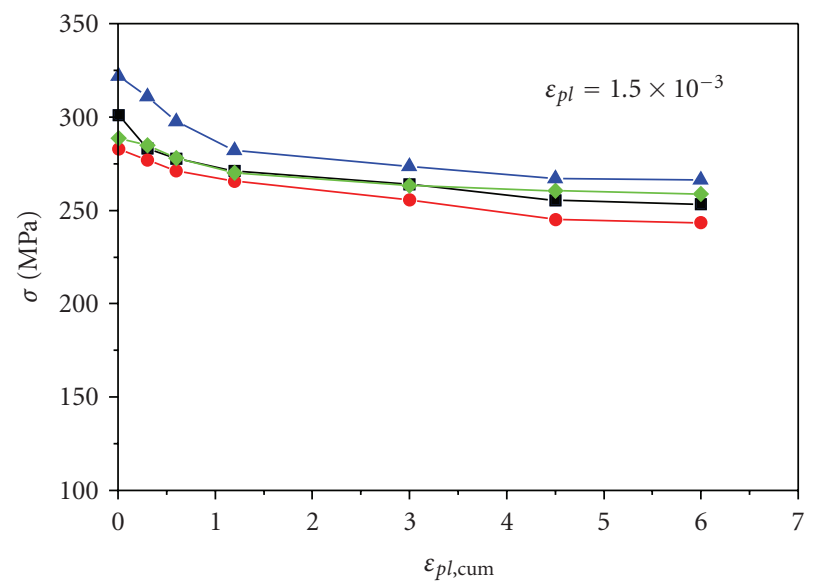

(b)

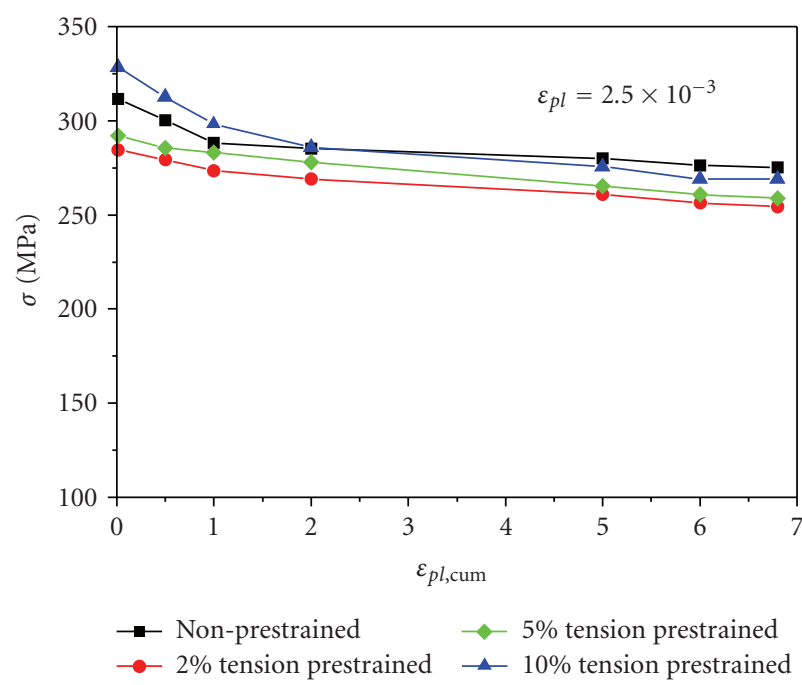

(c)

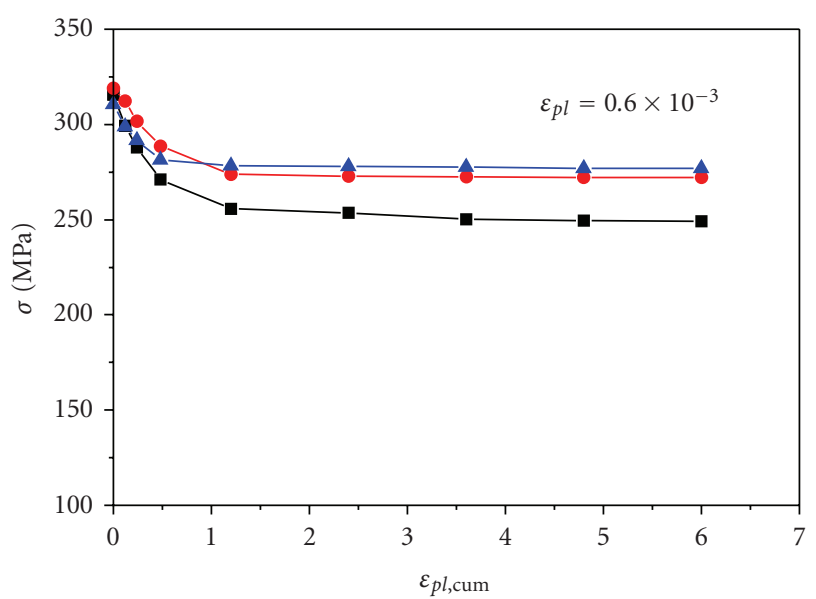

(d)

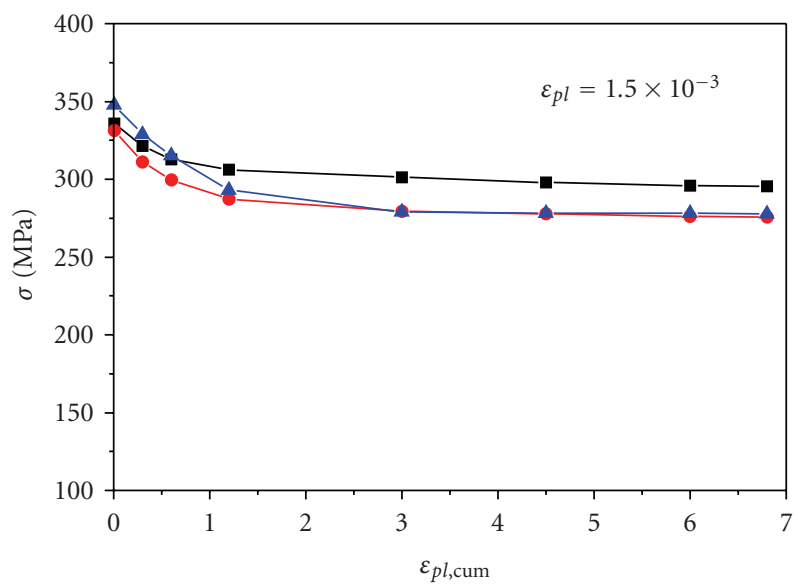

(e)

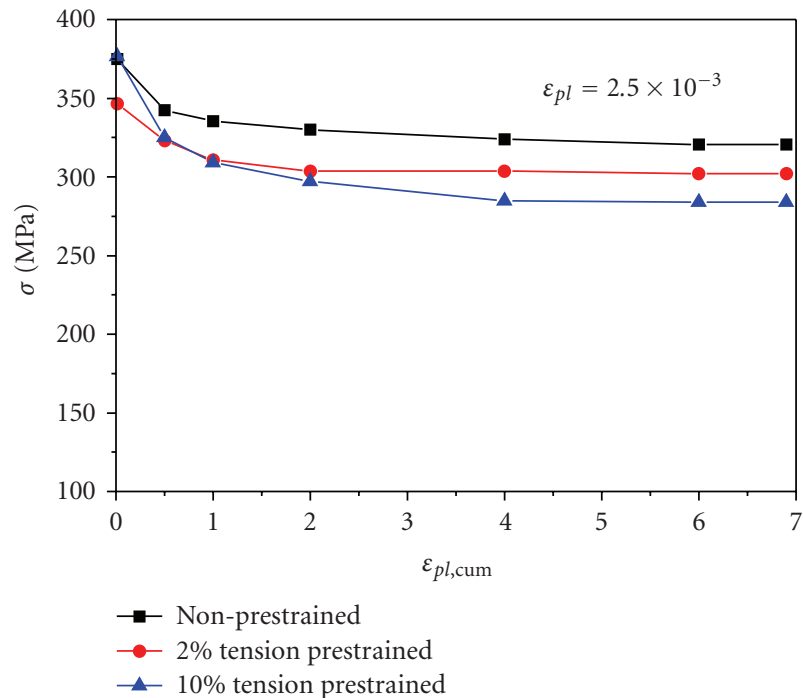

(f)

Figure 1: Cyclic softening curve of specimen with different tension prestraining amounts at various plastic strain amplitude, $(\mathrm{a})-(\mathrm{c}): \phi=0^{\circ}$; (d)-(f): $\phi=45^{\circ}$. 


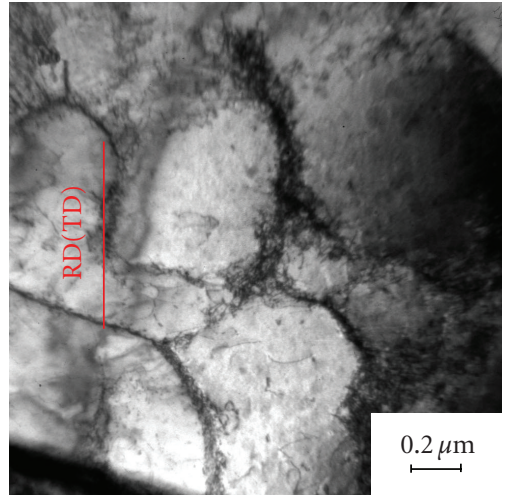

(a)

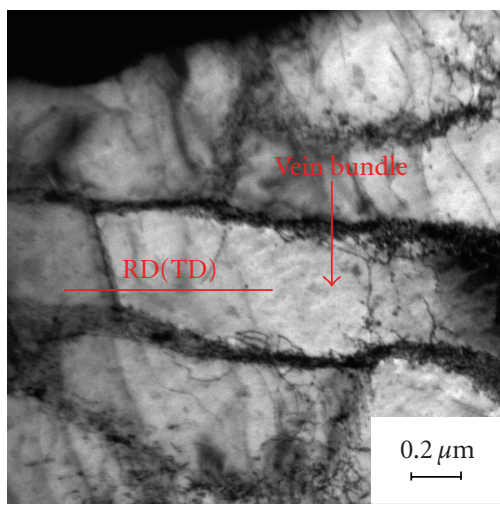

(d)

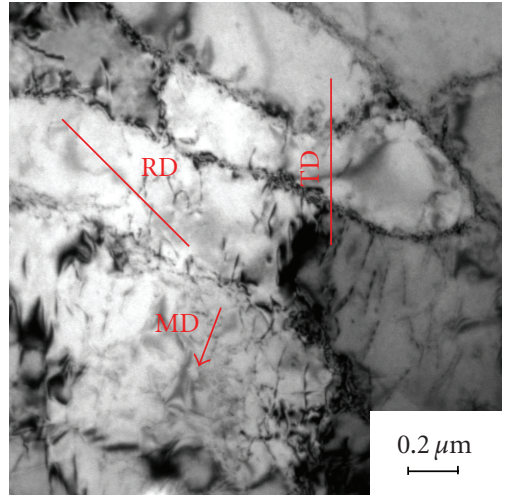

(b)

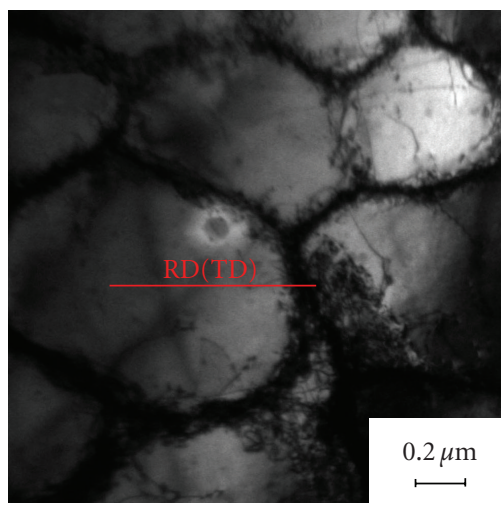

(e)

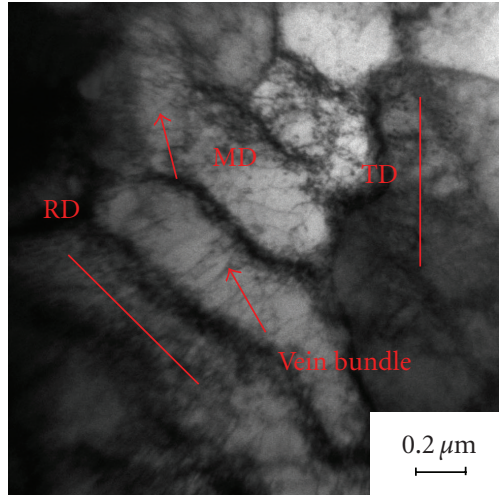

(c)

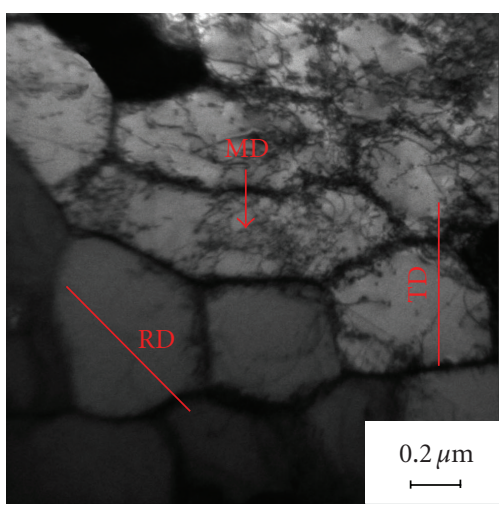

(f)

FIGURE 2: Saturation dislocation structure of specimens at various plastic strain amplitude with different preloading conditions $(\mathrm{a}) \varepsilon_{\mathrm{pl}}=$ $0.6 \times 10^{-3}$, non-prestrained, $\phi=0^{\circ}$; (b) $\varepsilon_{\mathrm{pl}}=0.6 \times 10^{-3}, 10 \%$ tension prestrained, $\phi=0^{\circ}$; (c) $\varepsilon_{\mathrm{pl}}=2.5 \times 10^{-3}, 2 \%$ tension prestrained, $\phi=45^{\circ}$; (d) $\varepsilon_{\mathrm{pl}}=1.5 \times 10^{-3}$, non-prestrained, $\phi=0^{\circ}$; (e) $\varepsilon_{\mathrm{pl}}=2.5 \times 10^{-3}, 10 \%$ tension prestrained, $\phi=0^{\circ} ;(\mathrm{f}) \varepsilon_{\mathrm{pl}}=2.5 \times 10^{-3}, 10 \%$ tension prestrained, $\phi=45^{\circ}$. $\mathrm{RD}=$ rolling direction, $\mathrm{TD}=$ testing direction, and $\mathrm{MB}=$ microband.

strain path. TEM images were taken by JEPL2100 microscope operated at an accelerating voltage of $200 \mathrm{KV}$.

\section{Results and Discussion}

3.1. Tension-Fatigue. In both cases, the cyclic softening curves with different plastic strain amplitudes and tension prestraining amounts are shown in Figures 1(a)-1(f). In general, for both cases, the higher tension prestraining amount results in a higher axial stress and the larger the cyclic softening rate at the initial stage under same strain amplitude. The saturation stress level at low prestrained is lower than that without prestrained, because the dislocation structures were rearranged at the end of cyclic deformation. In $\phi=45^{\circ}$ case, the axial stress at the beginning of reloading is a little higher than that of $\phi=0^{\circ}$ case under the same tension prestraining amount.

An explanation for above results can be reached from the study on evolution of dislocation structures. As in previous work [10-12], the higher tension prestraining amount, the higher dislocation density in the dislocation structures formed in the preloading, and the higher axial stress of specimens at the early stage of reloading in fatigue. Figures 2(a)-2(f) show that some exceptions about the rearranged dislocation structures are worth mentioning here. (i) While at the same low strain amplitude, only vein-bundle structures can be found in non-prestrained and low pretension samples; see Figures 2(c) and 2(d). (ii) in $\phi=45^{\circ}$ case, microbands embedded in cell structures have been detected in some grains after reloading in fatigue under relatively high plastic strain amplitude, Figures 2(b), 2(c), and 2(f), this is due to the occurrence of intense glide on one slip system that was inactive during the rolling.

\subsection{Fatigue Crack Growth}

$$
\frac{d a}{d N}=c(\Delta K)^{m}
$$

Figure 3 was obtained by Paris equation (1), where $c$ and $m$ are material constants. This curve may be divided into three regions $[13,14]$. As shown in Figure 3, the prestrained specimens show the faster propagation rates than do the corresponding nonprestrained specimens. Between the prestrained specimens, remarkable difference can be seen around $\Delta K_{\mathrm{th}}$, whereas the crack propagation rates are 


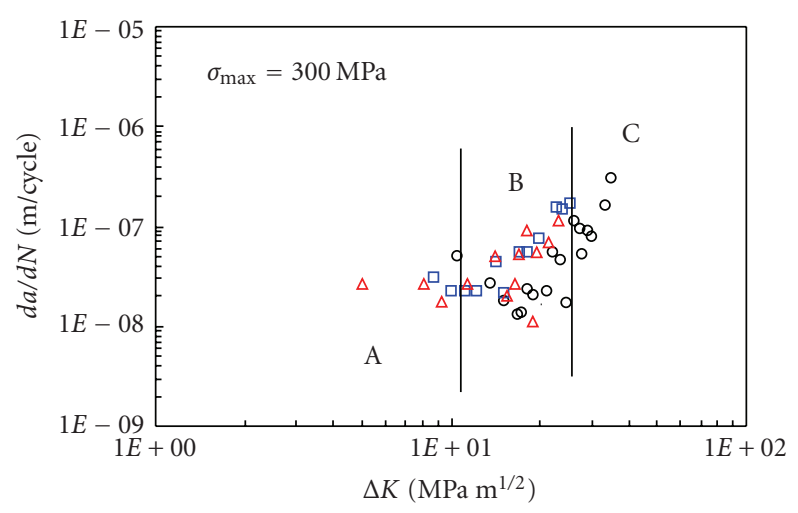

- Nonprestrained

口 $5 \%$ tension prestrained

$\triangle 10 \%$ tension prestrained

Figure 3: The $d a / d N$ versus $\Delta K$ for pretention specimens.

observed to be almost the same in the region of large $\Delta K$. It is well known that the prestrained specimens show a low value in the threshold stress intensity range. It is clear that the fatigue crack propagation behavior of Q235 steel is very sensitive to prestrained particularly in the near-threshold region.

\section{Conclusions}

(1) Cyclic deformation behavior of Q235 steel with tension prestraining at two amplitudes of strain path change was studied. For both cases, higher tension prestraining amount leads to higher axial stress at the beginning of cyclic deformation under the same strain amplitude. In the subsequent cyclic deformation, with increasing the cyclic number, the dislocation structure formed in preloading is resolved gradually. At the end of fatigue tests, for most specimens, the dislocation structures are almost the same as those of specimens as if the tension preloading did not happen. In $\phi=45^{\circ}$ case, the axial stress at the beginning of reloading is a little higher than that in $\phi=0^{\circ}$ case under the same tension prestraining amount.

(2) The experimental results show that with increasing the pretension deformation degree, the fatigue crack growth rate increases, especially at the near threshold section. The result of quantitative analysis shows that the pre-tension deformation reduced the fatigue crack growth threshold and increases the crack growth coefficient and consequently decreases the fatigue resistance of the part with mechanical damage.

\section{Acknowledgment}

This research is partially supported by High-Tech Research Center in Saitama Institute of Technology and University of Science and Technology Liaoning.

\section{References}

[1] S. Suresh, Fatigue of Materials, Cambridge University Press, Cambridge, UK, 1991.

[2] H.-J. Christ, G. Hoffmann, and O. Öttinger, "History effects in metals during constant and variable amplitude testingI: wavy dislocation glide behaviour," Materials Science and Engineering A, vol. 201, no. 1-2, pp. 1-12, 1995.

[3] D. C. Drucker and L. Palgen, "On stress-strain relations suitable for cyclic and other loading," Journal of Applied Mechanics, vol. 48, no. 3, pp. 479-485, 1981.

[4] J. H. Schmitt, J. V. Fernandes, J. J. Gracio, M. F. Vieira, and M. F. Vieira, "Plastic behaviour of copper sheets during sequential tension tests," Materials Science and Engineering A, vol. 147, no. 2, pp. 143-154, 1991.

[5] J. H. Schmitt, E. L. Shen, and J. L. Raphanel, "A parameter for measuring the magnitude of a change of strain path: validation and comparison with experiments on low carbon steel," International Journal of Plasticity, vol. 10, no. 5, pp. 535551, 1994.

[6] J.-V. Fernandes, L. F. Menezes, D. M. Rodrigues, B. M. Chaparro, and M. F. Vieira, "Non-uniform deformation after prestrain," European Journal of Mechanics, A/Solids, vol. 19, no. 2, pp. 209-221, 2000.

[7] W. P. Jia and J. V. Fernandes, "Cyclic deformation behaviour of copper polycrystalline prestrained in tension," Journal of Iron and Steel Research, vol. 22-26, pp. 508-511, 2002.

[8] M. F. Vieira, J. V. Fernandes, and B. Chaparro, "Yield stress after double strain-path change," Materials Science and Engineering A, vol. 284, no. 1-2, pp. 64-69, 2000.

[9] M. A. Pompetzki, T. H. Topper, and D. L. DuQuesnay, "The effect of compressive underloads and tensile overloads on fatigue damage accumulation in SAE 1045 steel," International Journal of Fatigue, vol. 12, no. 3, pp. 207-213, 1990.

[10] J. H. Schmitt, J. V. Fernandes, and J. J. Gracio, "Plastic behaviour of copper sheets during sequential tension tests," Materials Science and Engineering A, vol. 147, no. 2, pp. 143$154,1991$.

[11] J. V. Fernandes, J. J. Gracio, and J. H. Schmitt, Large Plastic Deformation: Fundamental Aspects andApplications to Metal Forming, edited by C. Teodosiu, J. L. Raphanel, and F. Sidoroff, Balkema, Rotterdam, The Netherlands, 1993.

[12] S. Pommier, "A study of the relationship between variable level fatigue crack growth and the cyclic constitutive behaviour of steel," International Journal of Fatigue, vol. 23, pp. S111-S118, 2001.

[13] B. Han, D. Y. Ju, and W. P. Jia, "Influence of water cavitation peening with aeration on fatigue behaviour of SAE1045 steel," Applied Surface Science, vol. 253, no. 24, pp. 9342-9346, 2007.

[14] B. Han, D. Y. Ju, and T. Nemoto, "Investigation on fatigue crack growth behaviour in S45C steel by water cavitation peening with aeration," Materials Science Forum, vol. 561-565, pp. 2485-2488, 2007. 

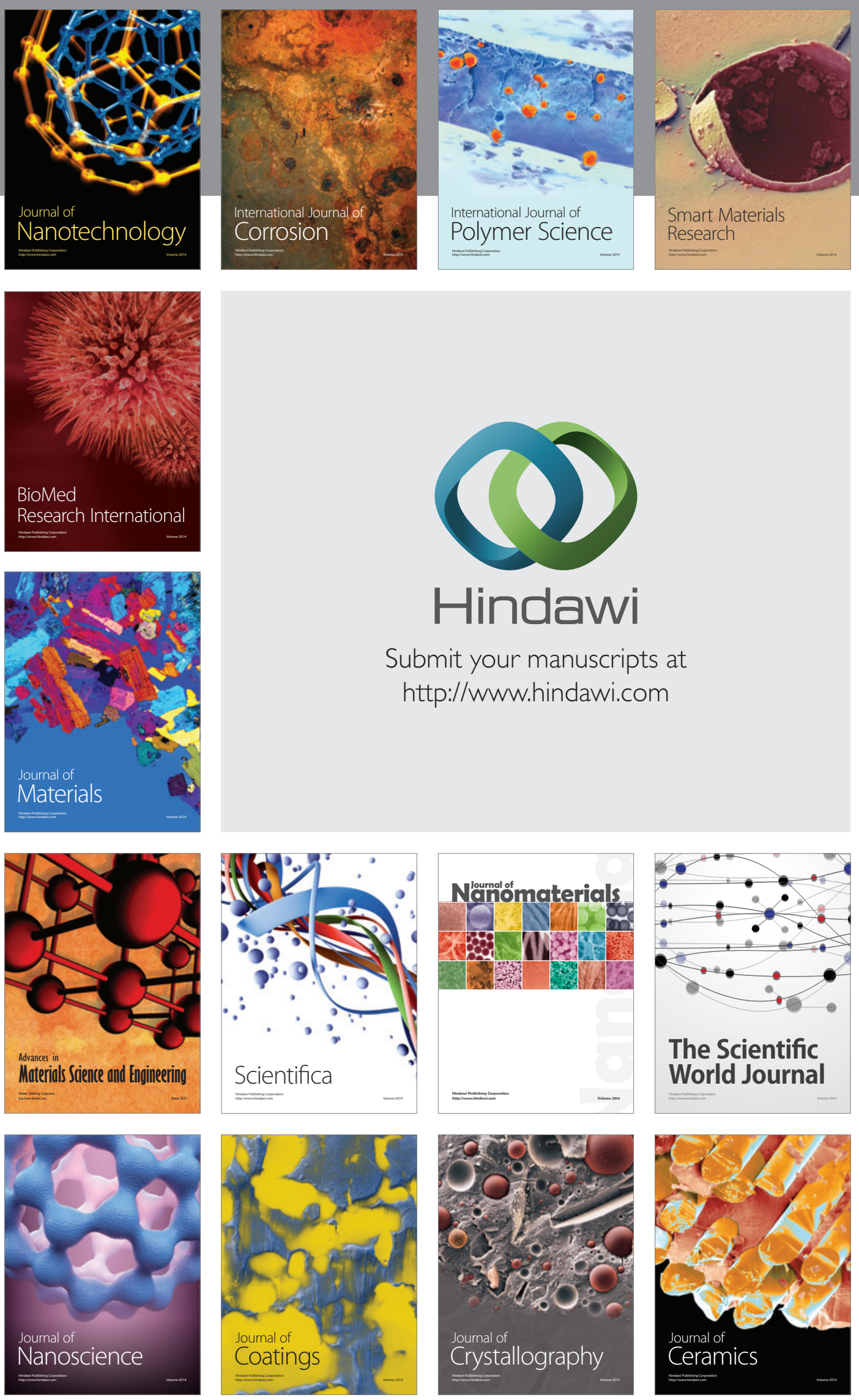

The Scientific World Journal

Submit your manuscripts at

http://www.hindawi.com

\section{World Journal}

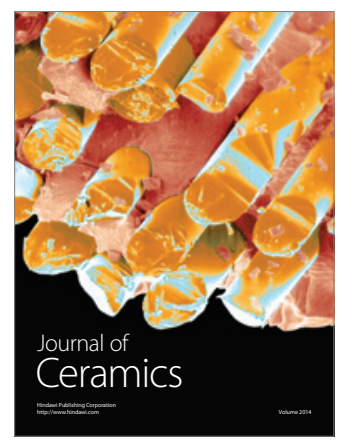

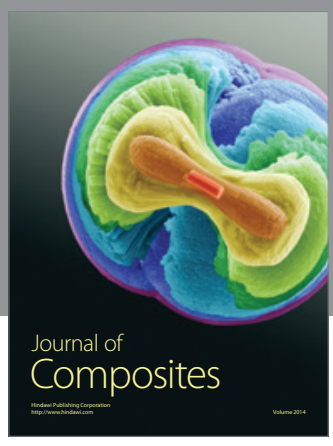
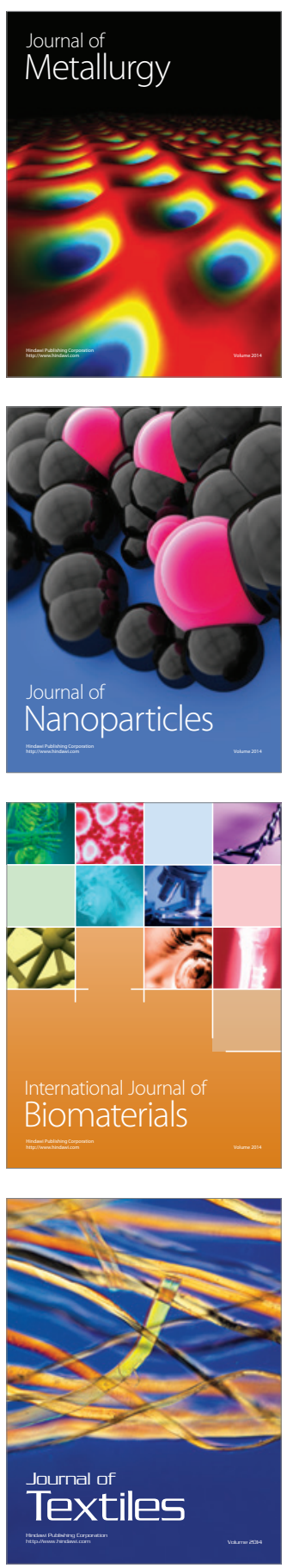